Supporting Information for

\title{
Improve Active Layer Morphology of All-polymer Solar Cells by Solution Temperature
}

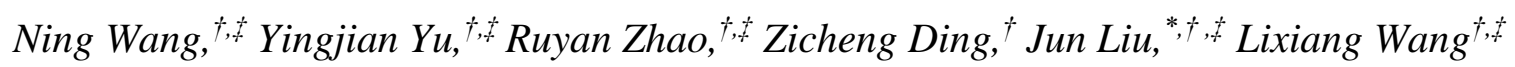

†State Key Laboratory of Polymer Physics and Chemistry, Changchun Institute of Applied Chemistry, Chinese Academy of Sciences, Changchun, 130022, P. R. China

University of Science and Technology of China, Hefei 230026, P. R. China

Corresponding Author

*E-mail: liujun@ciac.ac.cn (J.L.)

\section{Content}

1. Experimental details

2. All-PSC Device Fabrication

3. Opto-electronic properties

4. Hole and electron mobility

5. Device optimization

6. Polymer stacking behavior

7. Morphology analysis 


\section{Experimental details}

Materials. $\mathrm{CD} 1\left(M_{\mathrm{n}}=33.0 \mathrm{kDa}, \mathrm{PDI}=3.20\right)$ was synthesized in the laboratory. $\mathrm{PBN}-12\left(M_{\mathrm{n}}=\right.$ $34.4 \mathrm{kDa}$, PDI $=1.89$ ) was synthesized in the laboratory according our previous reported method.

Materials Characterization. Temperature-dependent UV-vis absorption spectra of CD1 and PBN-12 in solution were measured with a Perkin-Elmer Lambda $35 \mathrm{UV}$-vis spectrometer. The solution samples were prepared using chlorobenzene solvent with a concentration of $0.1 \mathrm{mg} \mathrm{mL}^{-}$ 1. Photoluminescence (PL) quenching test were performed with a Horiba fluorescence spectrophotometer. The pure and blend films were prepared from their chlorobenzene solution and annealed at $120{ }^{\circ} \mathrm{C}$ for $10 \mathrm{~min}$. The excitation wavelength was $540 \mathrm{~nm}$. The transmission electron microscopy (TEM) measurement was performed on a JEOL JEM-1400 transmission electron microscope operating at $120 \mathrm{kV}$. The atomic force microscopy (AFM) characterization was performed on a SPA $300 \mathrm{HV}$ instrument with a SPI 3800 controller (Seiko Instruments). A silicon micro cantilever (spring constant $2 \mathrm{~N} \mathrm{~m}^{-1}$ and resonance frequency ca. $300 \mathrm{kHz}$, Olympus Co., Japan) with an etched conical tip was used for the scan. The thickness of films was measured with a XP-plus Stylus Profilometer.

Hole- and Electron-Only Devices Fabrication and Mobility Measurements. The hole and electron mobilities were measured by SCLC method. The hole-only device structure is ITO/PEDOT:PSS (40 nm)/active layer/ $\mathrm{MoO}_{3}(10 \mathrm{~nm}) / \mathrm{Al}(100 \mathrm{~nm})$ and the electron-only device structure is ITO/PEIE $(10 \mathrm{~nm}) /$ active layer/Ca $(20 \mathrm{~nm}) / \mathrm{Al}(100 \mathrm{~nm})$, respectively. $J-V$ plots in the range of $0-10 \mathrm{~V}$ were measured using a Keithley 2400 source meter, and the mobility was obtained by fitting the $J-V$ plot near quadratic region according to the modified Mott-Gurney equation: 


$$
J=\frac{9}{8} \varepsilon_{r} \varepsilon_{0} \mu \frac{V^{2}}{L^{3}} \exp \left(0.89 \beta \frac{\sqrt{V}}{\sqrt{L}}\right)
$$

Where $J$ is the current density, $\varepsilon_{0}$ is permittivity of free space, $\varepsilon_{\mathrm{r}}$ is the relative permittivity (assumed to be 3), $\mu$ is the zero-field mobility, $V$ is the potential across the device $\left(V=V_{\text {applied }}-\right.$ $\left.V_{\mathrm{bi}}-V_{\text {series}}\right), \mathrm{L}$ is the thickness of active layer, and $\beta$ is the field-activation factor. The series and contact resistance of the device (10-20 $\Omega$ ) were measured using blank device of ITO/PEDOT:PSS/MoO$/ / \mathrm{Al}$ or ITO/PEIE/Ca/Al.

2D-GIWAXS Characterization. Two-dimensional grazing-incidence wide angle X-ray scattering (2D-GIWAXS) was measured at Shanghai Synchrotron Radiation Facility (SSRF) on beam line BL14B1 $(\lambda=0.124 \mathrm{~nm})$ with a MarCCD area detector at incidence angle of $0.16^{\circ}$. Samples were prepared on Si substrates using identical blend solutions as those used in devices.

\section{All-PSC Device Fabrication}

The all-polymer solar cell devices were fabricated with the configuration of ITO/PEDOT:PSS/active layer/LiF/Al. ITO glass substrates were cleaned by sequential ultrasonication in detergent, deionized water, acetone, and isopropyl alcohol, followed by drying at $120^{\circ} \mathrm{C}$ for $30 \mathrm{~min}$ and treating with UV-ozone for $25 \mathrm{~min}$. Then the PEDOT:PSS solution (Clevios VP Al 4083 from H. C. Starck Inc.) was spin-coated on the ITO glass substrates at 5000 $\mathrm{rpm}$ for $40 \mathrm{~s}$ to give a thickness of $40 \mathrm{~nm}$, and baked at $120^{\circ} \mathrm{C}$ for $30 \mathrm{~min}$. The PEDOT:PSS substrates were transferred to a nitrogen-filled glove box. CD1 and PBN-12 with a weight ratio of 1.5:1 was dissolved together in chlorobenzene $(\mathrm{CB})$ with a total concentration of $10 \mathrm{mg} \mathrm{mL}^{-1}$. The active layer solutions were prepared with different solution temperatures. The solution was stirred at different temperature for $6 \mathrm{~h}$ and not cooling, add $2.0 \mathrm{v} \% \mathrm{CN} 30$ minutes before spin coating, then the active layer was hot spin coating. The films thickness was maintained in the 
range of $80 \sim 100 \mathrm{~nm}$. The active layers were annealed at $120^{\circ} \mathrm{C}$ for $10 \mathrm{~min}$, after that, $0.5 \mathrm{~nm}$ $\mathrm{LiF}$ and $100 \mathrm{~nm} \mathrm{Al}$ were thermally deposited onto the active layer through a shadow mask in a vacuum chamber with a base pressure of $2 \times 10^{-4} \mathrm{~Pa}$. The effective area of the device was defined to be $0.08 \mathrm{~cm}^{2}$, which was further confined as $0.02 \mathrm{~cm}^{-2}$ by a non-refractive mask to improve the accuracy of measurements. The $J-V$ plots of the all-PSC devices were measured using a Keithley 2400 source meter under $100 \mathrm{~mW} \mathrm{~cm}{ }^{-2}$ AM $1.5 \mathrm{G}$ simulated solar light illumination provided by a XES-40S2-CE Class Solar Simulator (Japan, SAN-EI Electric Co., Ltd.). An aperture with an area of $2 \mathrm{~mm}^{2}$ was used to accurately measure the device performance. The EQE spectra were measured using a Solar Cell Spectral Response Measurement System QE-R3011 (Enlitech Co., Ltd.) under the short-circuit condition at a chopping frequency of $165 \mathrm{~Hz}$. 


\section{Opto-electronic properties}

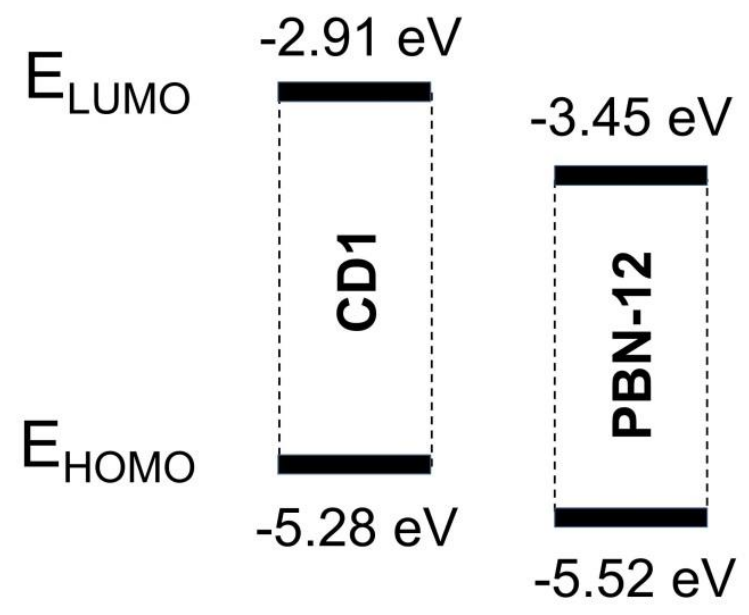

Figure S1. Energy level diagram of CD1 and PBN-12.

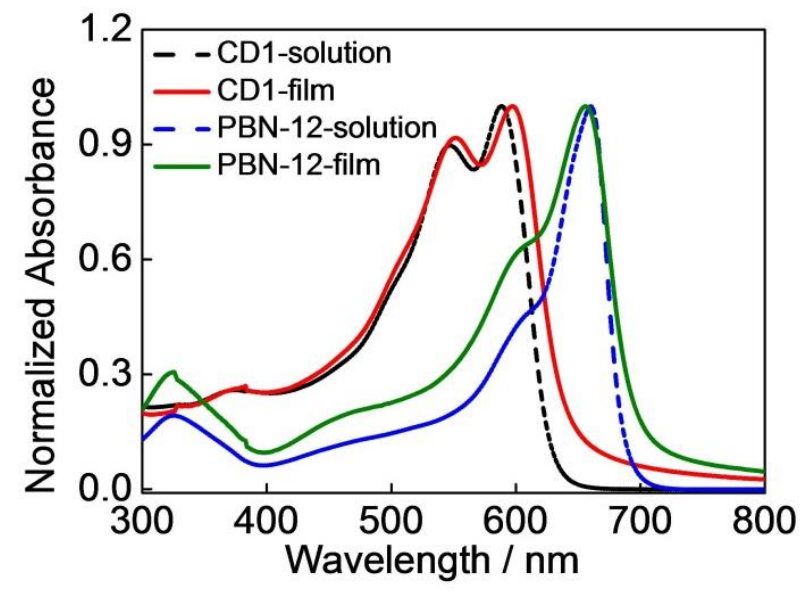

Figure S2. UV-vis absorption spectra of CD1 and PBN-12 in chlorobenzene solutions in thin films. 


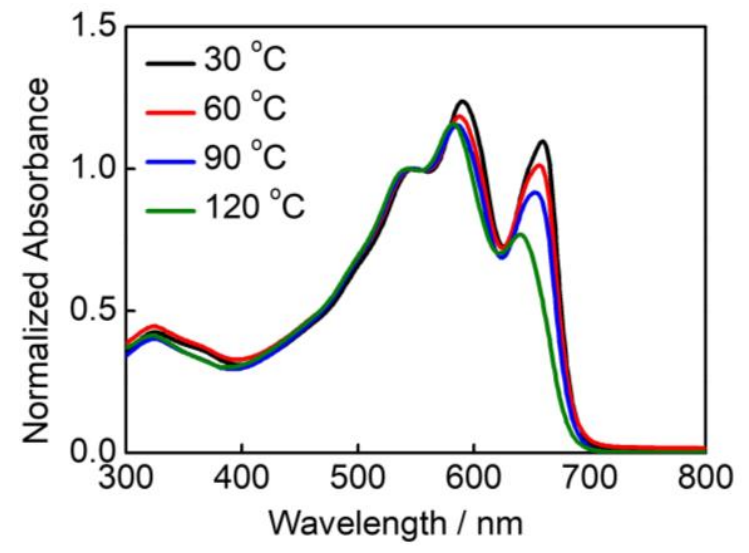

Figure S3. The temperature-dependent UV-vis absorption spectra of CD1:PBN-12 blend in chlorobenzene solutions.

\section{Hole and electron mobility}

(a)

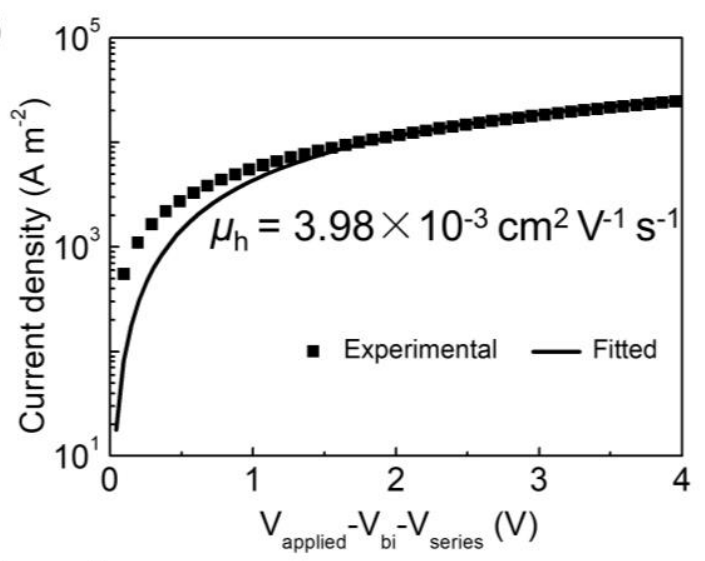

(b)

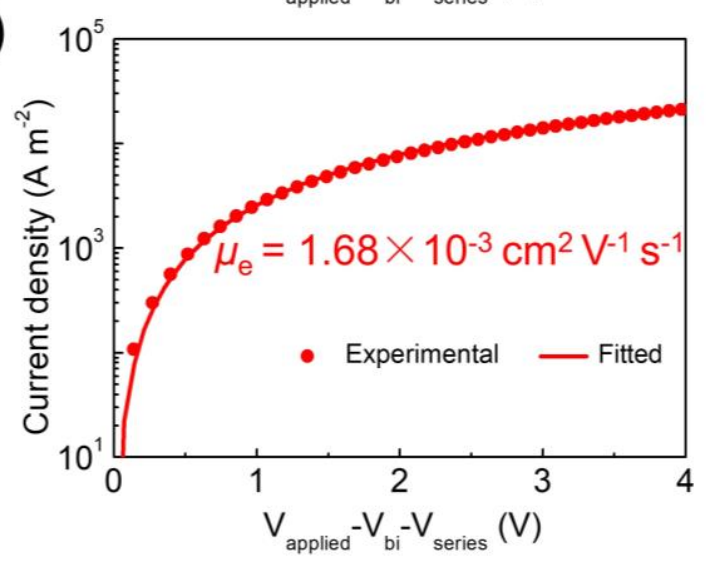

Figure S4. The space-charge-limited $J-V$ plots from the (a) hole-only device based on pure CD1 film and (b) electron-only device based on pure PBN-12 film. 
(a)

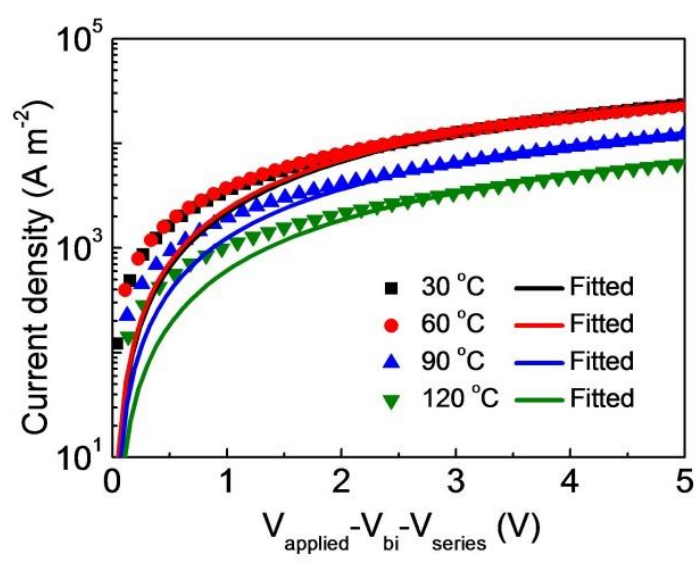

(b)

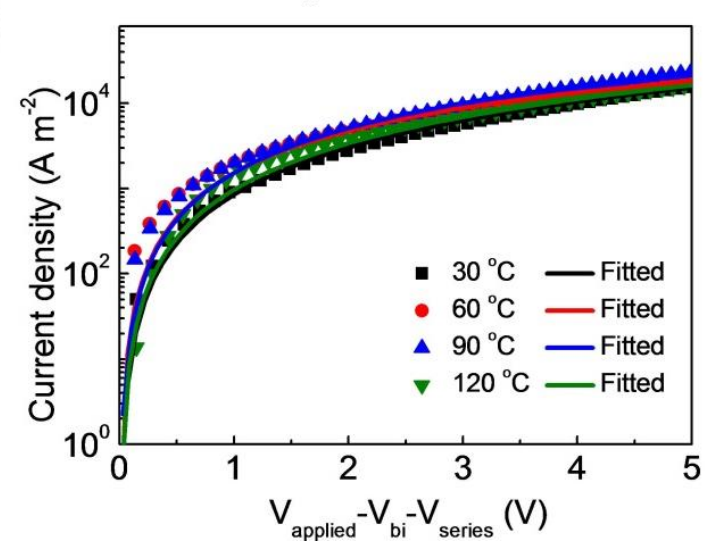

Figure S5. The space-charge-limited $J-V$ plots from the (a) hole-only and (b) electron-only devices based on CD1:PBN-12 blend with different solution temperatures. 


\section{Device optimization}

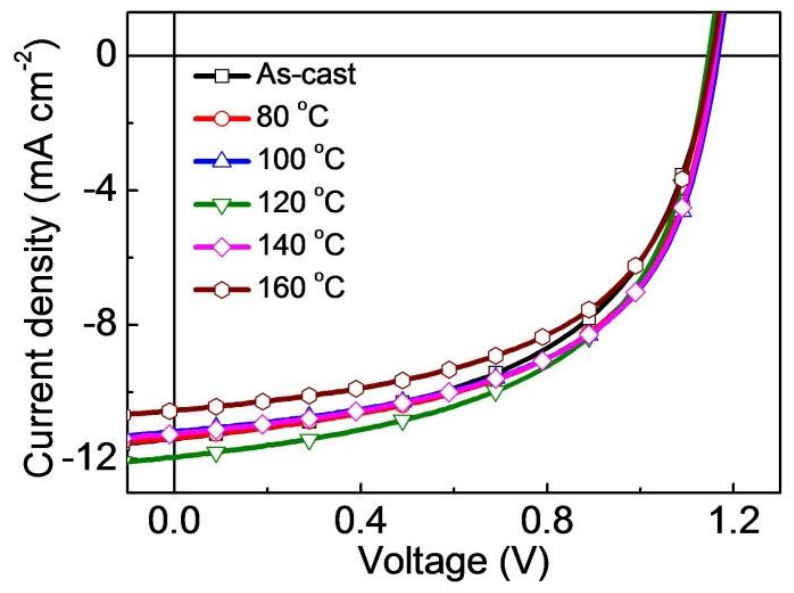

Figure S6. $J-V$ plots of the all-PSCs based on CD1:PBN-12 blend with the active layer as-cast and annealed for 10 minutes at different thermal annealing temperatures.

Table S1. Photovoltaic Performance of the all-PSCs based on CD1:PBN-12 blend with the active layer as-cast and annealed for 10 minutes at different thermal annealing temperatures.

\begin{tabular}{lcccc}
\hline $\begin{array}{l}\text { Active } \\
\text { layers }\end{array}$ & $\begin{array}{c}V_{\mathrm{OC}} \\
(\mathrm{V})\end{array}$ & $\begin{array}{c}J_{\mathrm{SC}} \\
\left(\mathrm{mA} \mathrm{cm}^{-2}\right)\end{array}$ & $\begin{array}{c}\mathrm{FF} \\
(\%)\end{array}$ & $\begin{array}{c}\mathrm{PCE} \\
(\%)\end{array}$ \\
\hline As-cast & 1.16 & 11.39 & 53.4 & 7.06 \\
$80^{\circ} \mathrm{C}$ & 1.16 & 11.36 & 55.7 & 7.34 \\
$100^{\circ} \mathrm{C}$ & 1.17 & 11.17 & 56.4 & 7.37 \\
$120^{\circ} \mathrm{C}$ & 1.16 & 11.93 & 54.4 & 7.53 \\
$140^{\circ} \mathrm{C}$ & 1.16 & 11.24 & 56.6 & 7.38 \\
$160^{\circ} \mathrm{C}$ & 1.15 & 10.55 & 55.5 & 6.73 \\
\hline
\end{tabular}




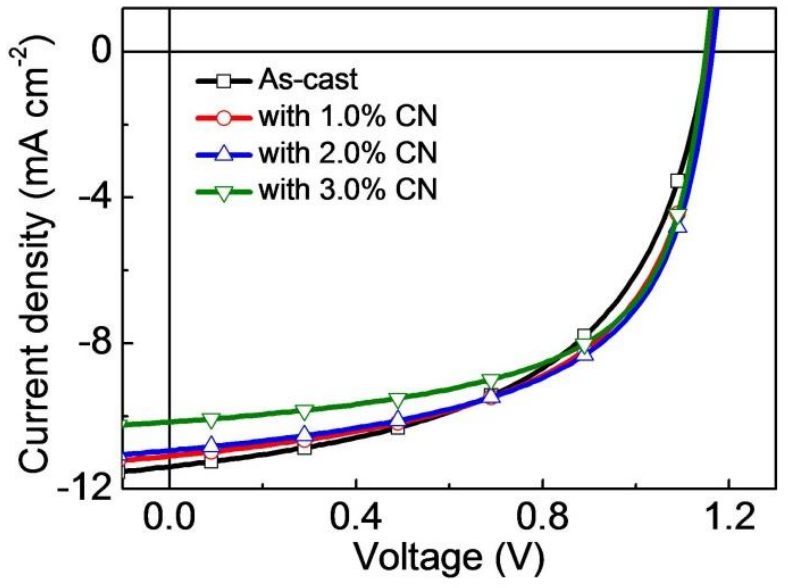

Figure S7. $J-V$ plots of the all-PSCs based on CD1:PBN-12 blend with the active layer as-cast and different contents of chloronaphthalene $(\mathrm{CN})(\mathrm{v} \%)$.

Table S2. Photovoltaic Performance of the all-PSCs based on CD1:PBN-12 blend with the active layer as-cast and different contents of chloronaphthalene $(\mathrm{CN})$ additive ( $\mathrm{v} \%)$.

\begin{tabular}{lcccc}
\hline $\begin{array}{l}\text { Active } \\
\text { layers }\end{array}$ & $\begin{array}{c}V_{\mathrm{OC}} \\
(\mathrm{V})\end{array}$ & $\begin{array}{c}J_{\mathrm{SC}} \\
\left(\mathrm{mA} \mathrm{cm}^{-2}\right)\end{array}$ & $\begin{array}{c}\mathrm{FF} \\
(\%)\end{array}$ & $\begin{array}{c}\text { PCE } \\
(\%)\end{array}$ \\
\hline As-cast & 1.16 & 11.39 & 53.4 & 7.06 \\
$1.0 \% \mathrm{CN}$ & 1.16 & 11.10 & 56.6 & 7.29 \\
$2.0 \% \mathrm{CN}$ & 1.16 & 10.95 & 58.4 & 7.41 \\
$3.0 \% \mathrm{CN}$ & 1.15 & 10.55 & 61.2 & 7.18 \\
\hline
\end{tabular}




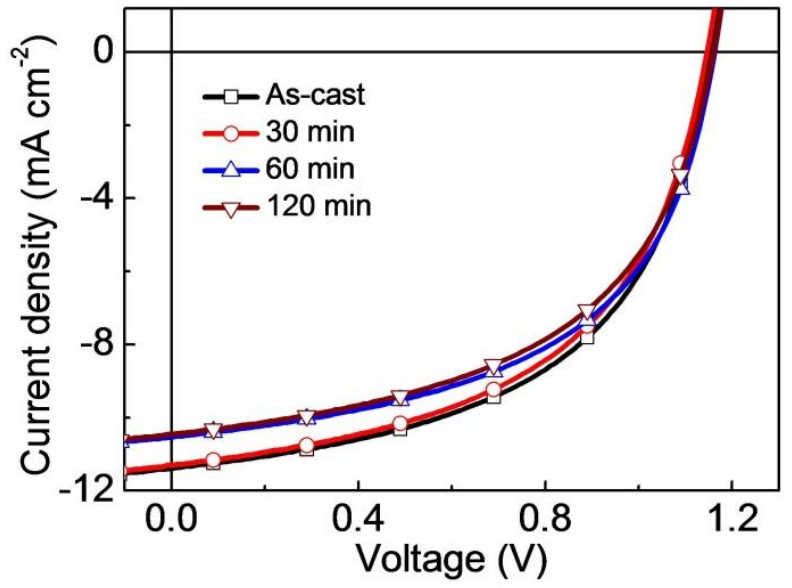

Figure S8. $J-V$ plots of the all-PSCs based on CD1:PBN-12 blend with the active layer as-cast and solvent annealing for different time.

Table S3. Photovoltaic Performance of the all-PSCs based on CD1:PBN-12 blend with the active layer as-cast and solvent annealing for different time.

\begin{tabular}{lcccc}
\hline $\begin{array}{l}\text { Active } \\
\text { layers }\end{array}$ & $\begin{array}{c}V_{\mathrm{OC}} \\
(\mathrm{V})\end{array}$ & $\begin{array}{c}J_{\mathrm{SC}} \\
\left(\mathrm{mA} \mathrm{cm}^{-2}\right)\end{array}$ & $\begin{array}{c}\mathrm{FF} \\
(\%)\end{array}$ & $\begin{array}{c}\text { PCE } \\
(\%)\end{array}$ \\
\hline As-cast & 1.16 & 11.39 & 53.4 & 7.06 \\
$30 \mathrm{~min}$ & 1.16 & 11.31 & 52.1 & 6.84 \\
$60 \mathrm{~min}$ & 1.16 & 10.53 & 53.6 & 6.55 \\
$120 \mathrm{~min}$ & 1.15 & 10.45 & 52.2 & 6.33 \\
\hline
\end{tabular}




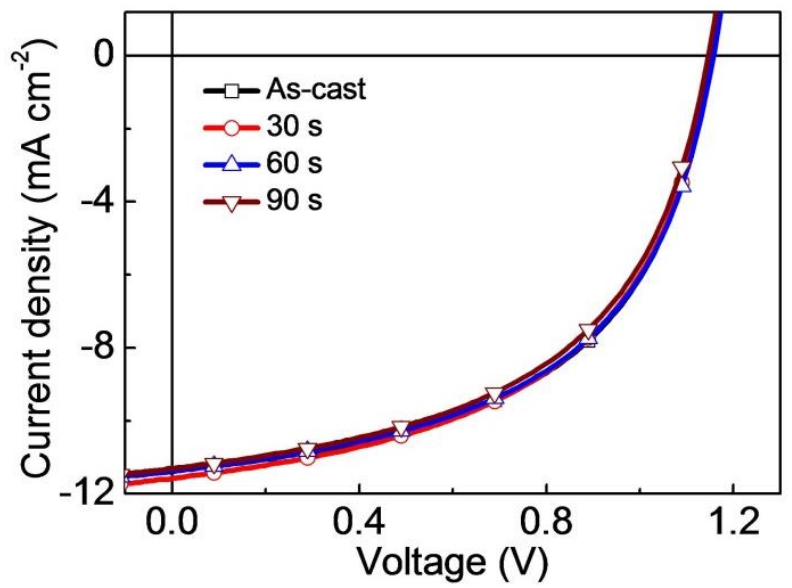

Figure S9. $J-V$ plots of the all-PSCs based on CD1:PBN-12 blend with the active layer as-cast and solvent vapor annealing for different time.

Table S4. Photovoltaic Performance of the all-PSCs based on CD1:PBN-12 blend with the active layer as-cast and solvent vapor annealing for different time.

\begin{tabular}{lcccc}
\hline $\begin{array}{l}\text { Active } \\
\text { layers }\end{array}$ & $\begin{array}{c}V_{\mathrm{OC}} \\
(\mathrm{V})\end{array}$ & $\begin{array}{c}J_{\mathrm{SC}} \\
\left(\mathrm{mA} \mathrm{cm}^{-2}\right)\end{array}$ & $\begin{array}{c}\mathrm{FF} \\
(\%)\end{array}$ & $\begin{array}{c}\text { PCE } \\
(\%)\end{array}$ \\
\hline As-cast & 1.16 & 11.39 & 53.4 & 7.06 \\
$30 \mathrm{~s}$ & 1.16 & 11.58 & 51.9 & 6.97 \\
$60 \mathrm{~s}$ & 1.16 & 11.38 & 52.7 & 6.96 \\
$90 \mathrm{~s}$ & 1.15 & 11.31 & 52.1 & 6.78 \\
\hline
\end{tabular}




\section{Polymer stacking behavior}
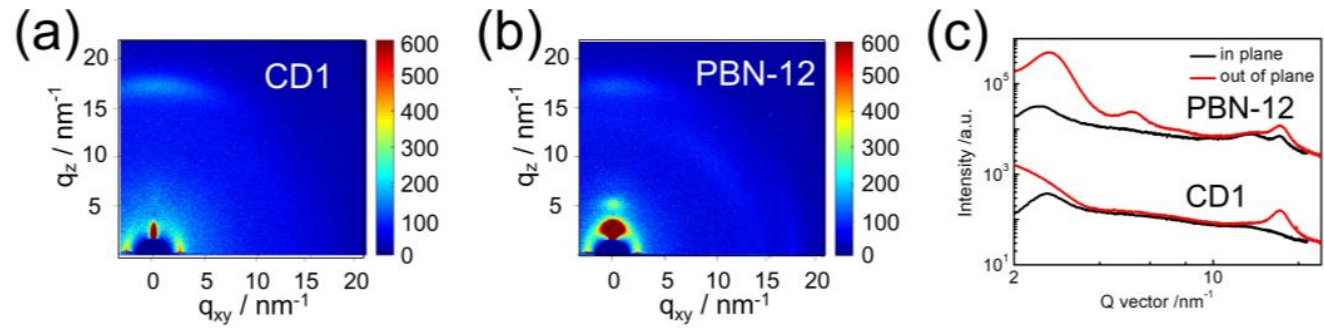

Figure S10. 2D-GIWAXS of (a) pure CD1 film and (b) pure PBN-12 film. (c) 1D linecuts of the corresponding 2D-GIWAXS patterns in the in-plane and out-of-plane directions.

Table S5. 2D-GIWAXS characterization data of pure CD1 film and pure PBN-12 film processed with different solution temperatures.

\begin{tabular}{|c|c|c|c|c|c|c|c|c|c|}
\hline \multirow[b]{2}{*}{ Films } & \multirow[b]{2}{*}{ Directions } & \multicolumn{4}{|c|}{100} & \multicolumn{4}{|c|}{010} \\
\hline & & $\begin{array}{c}\text { Location } \\
{\left[\AA^{-1}\right]}\end{array}$ & $\begin{array}{c}\text { d-spacing } \\
{[\AA]}\end{array}$ & $\begin{array}{c}\text { FWHM } \\
{\left[\AA^{-1}\right]}\end{array}$ & $\begin{array}{l}C L \\
{[\AA]}\end{array}$ & $\begin{array}{c}\text { Location } \\
{\left[\AA^{-1}\right]}\end{array}$ & $\begin{array}{c}\text { d-spacing } \\
{[\AA]}\end{array}$ & $\begin{array}{c}\text { FWHM } \\
{\left[\AA^{-1}\right]}\end{array}$ & $\begin{array}{l}\text { CL } \\
{[\AA]}\end{array}$ \\
\hline \multirow{2}{*}{ CD1 } & Out-of- plane & & & & & 1.72 & 3.51 & 0.185 & 25 \\
\hline & In-plane & 0.26 & 24.17 & 0.146 & 39 & & & & \\
\hline \multirow{2}{*}{ PBN-12 } & Out-of- plane & 0.27 & 23.48 & 0.106 & 53 & & & & \\
\hline & In-plane & 0.25 & 25.23 & 0.118 & 48 & 1.72 & 3.65 & 0.300 & 19 \\
\hline
\end{tabular}

\section{Morphology analysis}

(a)

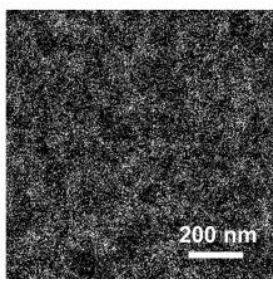

(b)

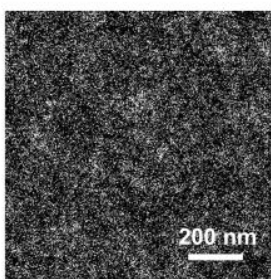

(c)

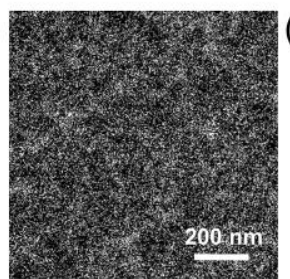

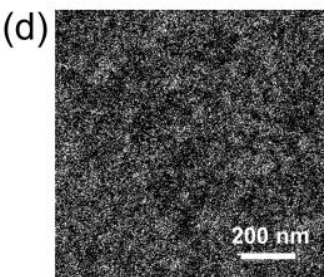

Figure S11. Transmission electron microscopy (TEM) images of CD1: PBN-12 blend with different solution temperatures: (a) $30{ }^{\circ} \mathrm{C}$, (b) $60{ }^{\circ} \mathrm{C}$, (c) $90{ }^{\circ} \mathrm{C}$ and (d) $120{ }^{\circ} \mathrm{C}$. 